\title{
Public Sector Reform and the State of Performance Management in Portugal: is there a gap between performance measurement and its use?
}

\author{
Ana I. Melo \\ School of Technology and Management (ESTGA), University of Aveiro \\ Centre for Research in Higher Education Policies (CIPES), University of Aveiro \\ Luís F. Mota \\ Research Unit on Governance, Competitiveness and Public Policies (GOVCOPP), \\ University of Aveiro, \\ School of Technology and Management, Polytechnic Institute of Leiria \\ Published in the International Journal of Public Sector Management \\ DOI: https://doi.org/10.1108/IJPSM-12-2019-0325
}

\section{$\underline{\text { Please cite as: }}$}

Melo, A.I. and Mota, L.F. (2020), "Public sector reform and the state of performance management in Portugal: is there a gap between performance measurement and its use?", International Journal of Public Sector Management, Vol. ahead-of-print No. ahead-ofprint. https://doi.org/10.1108/IJPSM-12-2019-0325

\section{Deposit license:}

This author accepted manuscript is deposited under a Creative Commons Attribution Non-commercial 4.0 International (CC BY-NC) licence. This means that anyone may distribute, adapt, and build upon the work for non-commercial purposes, subject to full attribution. If you wish to use this manuscript for commercial purposes, please contact permissions@emerald.com. 


\title{
Public Sector Reform and the State of Performance Management in Portugal: is there a gap between performance measurement and its use?
}

\author{
Ana I. Melo and Luís F. Mota ${ }^{1}$
}

\begin{abstract}
Purpose - This paper analyses the state of performance management in the Portuguese public sector as part of the efforts towards public administration reform.

Design/methodology/approach -Theoretically, we took Bouckaert and Halligan's (2008, pp. 35-39) approach into consideration to analyse the adoption of performance management practices. This approach was supplemented by an adaptation of Pollitt and Bouckaert's (2011, p. 33) framework to analyse the context for administrative reforms. The used data analysis techniques include documentary analysis (namely legislation and evaluation reports of reform efforts), secondary data analysis and a survey conducted with 296 Portuguese top public managers.

Findings -Findings show that Portuguese public sector organizations adopted several tools to measure performance over the years, but failed to incorporate performance information into their management practices or to properly use it for either internal or external purposes. Concerning the ideal types proposed by Bouckaert and Halligan (2008, p. 36), Portugal is considered to fit the 'Performance Administration' ideal type, even though it is moving closer to the 'Managements of Performance' ideal type.

Originality - This is one of the first comprehensive studies on the state of performance management in Portugal framed within the broader context of public sector reforms. The findings will be of interest both to scholars that study public administration reforms and performance management and to Portuguese policy makers and public managers who are interested in understanding and improving the way performance information is measured, incorporated and used in that sector.
\end{abstract}

Keywords: performance management, public sector reform, public administration, Portugal

\footnotetext{
${ }^{1}$ The authors wish to thank the comments from the reviewers and editor. The second author wishes to thank the support from Fundação para a Ciência e a Tecnologia, the Portuguese Agency of Science and Technology, through a post-doctoral fellowship (SFRH/BPD/115117/2016) he was receiving when the first version of the paper was written. This work was also financially supported by the research unit on Governance, Competitiveness and Public Policy (GOVCOPPUA, project POCI-01-0145-FEDER-008540), funded by FEDER funds through COMPETE2020 - Programa Operacional Competitividade e Internacionalização (POCI) - and by national funds through FCT - Fundação para a Ciência e a Tecnologia.
} 


\section{Introduction}

For a long period, the concept of management was barely applied to the public sector. Since the 1980s, new political orientations and economic, technological and social changes have been pressuring several governments to adopt a set of reforms - often labelled under the umbrella of New Public Management (NPM) -, so that their public sectors could become more competitive, efficient, flexible and responsive (Pollitt and Bouckaert, 2011, p. 2).

One of the ideas advocated by NPM was a focus on explicit standards and measures of performance, preferably quantitative, with the justification that goals should be clearly stated in order to promote accountability and efficiency (Kroll, 2015; Van Dooren and Hoffmann, 2018). As a result, the use of tools such as performance budgeting, rankings, performance targets in contracting-out relations or performance-related pay became more frequent in the public sector (Van Dooren and Hoffmann, 2018).

The issue of performance management thus became a very important topic in public administration scientific domains, with multiple focuses. On the one hand, there has been a focus on micro- and meso-management factors that try to explain differences in the implementation and results of performance management systems - see, for instance, Van Dooren and Van de Walle (2008), Van Dooren et al. (2010) or Moynihan and Hawes (2012). Kroll (2015), for instance, mentions that the actual use of performance indicators depends on important drivers, such as the involvement of stakeholders, the commitment from organizational leaders, the existence of support capacity, an innovative culture or clarity of goals. On the other hand, some research has focused on the adoption of performance management systems framed on broader public administration reform efforts - see, for instance, Bouckaert and Halligan (2008) or Rhodes et al. (2012). Some of these studies have concluded that the implementation of performance management as a reform tool had different intensities and trajectories of implementation and different impacts in distinct countries.

This paper is aligned with the second research trend and aims to analyse the state of performance management in the Portuguese public sector as part of the efforts towards public administration reform. The importance of such an analysis stems from the fact this is a rather unexplored national context since most of the analyses regarding performance management are focused on Anglo-Saxon and northern and central European countries (e.g. Bouckaert and Halligan, 2008; Lægreid and Verhoest, 2010; Pollitt and Bouckaert, 2011).

Traditionally seen as a 'laggard' regarding public sector reform, Portugal has nevertheless adopted several public sector managerial-oriented reforms since the $1980 \mathrm{~s}$, and more strongly since the beginning of the $21^{\text {st }}$ century (Magone, 2011). Apart from some generic analyses of the evolution of the public sector reform (e.g. Rocha and Araújo, 2007; Corte-Real, 2008; Magone, 2011; Mota et al., 2016), little is known about their 
impacts on specific domains, such as performance management. The scant existing research is mostly focused on the adoption of certain policy measures (e.g. Araújo and Branco, 2009; Madureira, 2016) or on the organizational factors that influence the adoption of performance management systems (e.g. Gomes et al., 2017). Thus the need for a more comprehensive analysis such as this.

To achieve the aforementioned goal, we have taken Bouckaert and Halligan's (2008, pp. 35-39) approach into consideration to analyse the adoption of performance management practices, namely regarding the measurement, incorporation and use of performance information. This approach was supplemented by an adaptation of Pollitt and Bouckaert's (2011, p. 33) framework to analyse the context and trajectories of administrative reforms.

Mixed techniques were used to collect data. These included documentary analysis, namely legislation and evaluation reports of reform efforts, and secondary data analysis. Additionally, we also analysed the results of a set of questions from a survey conducted with 296 top public managers from the Portuguese Central Public Administration, integrated into the COCOPS project ${ }^{2}$.

The paper is structured in the following way: first, the theoretical framework is presented, including the concept of performance management used and the approach used for analysing the state of performance management at a country level; second, the techniques used to collect data are explained; third, the state of performance management in Portugal is analysed; and, finally, conclusions are drawn, enabling the classification of Portugal in one of the ideal types of public sector performance systems proposed by Bouckaert and Halligan (2008, pp. 36-39).

\section{Literature Review}

\subsection{The concept of performance management: a systems view}

Although the practice of performance management is not something new, it has been revived with the advent of NPM, which, amongst other things, advocated managerial freedom based on output control (Van de Walle and Van Dooren, 2008). In exchange for more autonomy and flexibility in the use of allocated resources and in choosing the means and methods, many public organizations had to accept more rigid performance management systems (Lægreid et al., 2008).

\footnotetext{
${ }^{2}$ The project Coordinating for Cohesion in the Public Sector of the Future (COCOPS) was developed between 2011 and 2014 with the aim to assess the impact of NPM reforms in European countries. It originally comprised 10 European countries but its work package dedicated to survey top public managers was launched in 17 countries, including Portugal. For more information, see https://www.hertie-school.org/en/cocops.
} 
In fact, in the early 1990s, and especially in OECD countries, many public service organizations from different areas focused on developing performance indicators and targets. Since then, performance management has become increasingly systematic, specialized, professionalized and institutionalized in the public sector (Van Dooren, 2006).

Within the scope of this paper, performance management is defined as an integrated system where performance information is closely linked to strategic steering. As Pollitt (2013, pp. 346-347) argues, performance management is a system in which "organizations and individuals are given objectives, measurable targets are derived from the objectives, and then a wide variety of instruments of authority or incentive are deployed to encourage staff to hit or exceed their targets".

After having formulated the intended goals and targets, performance management consists of three stages: the first is the measurement stage, which involves assessing, either quantitatively or qualitatively, the input, output, level of activity or outcome of organizations, people and programmes, thereby gathering performance information (Askim, 2008; Radnor and Barnes, 2007); the second is the reporting stage, which entails communicating performance information to decision-makers so that they can decide what to do; and the third is the management stage, which consists of using the information and acting upon it, aiming at improvements in behaviour, motivation and processes (Radnor and Barnes, 2007; Bouckaert and Van Dooren, 2003). The latter stage is the most crucial indicator of whether performance is worth the effort (Hatry, 2006). It is also the most challenging aspect of performance, requiring individuals and organizations to change deeply entrenched decision-making behaviours (Moynihan, 2008).

Given the importance of linking the measurement process with strategic planning, the need for a closed-loop between the actions of performance measuring, taking corrective action and achieving outcome response is widely recognized (Boland and Fowler, 2000). This means that, after being collected, performance data should be used to provide information on important matters, promote appropriate behaviour, provide mechanisms for accountability and control, and create a mechanism for intervention and learning (Haas and Kleingeld, 1998). Hansen (2017) argues that the generated performance data should be used to motivate, make decisions and to document and improve performance. According to Hammerschmid et al. (2013), the information collected on performance can be used for internal purposes, such as to monitor staff performance, identify problems and foster learning, or for external purposes, such as communicating with citizens, engaging with stakeholders or managing the organizations' image. 


\subsection{Framework for analysing performance management at a country level}

In order to provide a consistent basis for analysing the state of performance management in Portugal, Bouckaert and Halligan's (2008, pp. 35-39) approach was used to look at the adoption of performance management practices, supplemented by Pollitt and Bouckaert's (2011, p. 33) framework to analyse the context and trajectory of administrative reforms. As the focus of this research is to conduct the analysis at a macro level and not at a micro or meso level, a framework comprising these two contributions was considered the most adequate one to conduct the present study.

\subsubsection{The context for performance management}

Bouckaert and Halligan (2008, pp. 3, 40), in their book "Managing performance: international comparisons", highlight the importance of examining the public management context within which public sector performance management is undertaken since NPM reforms were being implemented differently in distinct contexts.

One of the first studies which concluded that NPM was being implemented with different directions and paces in different (groups of) countries was that published by Pollitt and Bouckaert in 2000, which has been updated afterwards (Pollitt and Bouckaert, 2011). This study also highlighted the importance of examining the public sector context to understand how and why administrative reforms are undertaken in the public sector. The contextual factors described by Pollitt and Bouckaert (2011, p. 33) were considered relevant for an assessment of performance management, namely socio-economic forces, the political system and the administrative system (Rhodes et al., 2012).

Socio-economic forces are largely captured by analysing socio-economic statistics on citizens and the economy, but also include global socio-economic factors deemed to affect the target country, population demographics and socio-economic policies (Rhodes et al., 2012). In this paper, the analysis of socio-economic forces has been divided into socio-demographic changes, global economic forces and socio-economic policies.

The political system incorporates not only the degree of centralization and location of political power, but also society's pressure for change, and ruling parties' main ideas (Rhodes et al., 2012).

The administrative system is regarded as a complex set of elements, of which we have selected the administrative culture and the public sector reform agenda and trajectory as most relevant to the context for performance management, following Rhodes's et al. (2012) analysis. Moreover, the study also takes the administrative culture into consideration, which may be either 'Weberian', when it is deeply rooted in the law, it being the primary role of the civil service to carry out the law, or of 'public interest', when the civil service is less closely tied to the legal framework within which it operates and understands itself to have a 'public interest' mandate. Finally, Pollitt and Bouckaert 
(2011, pp. 115-118) take the trajectories of the reform into consideration, which can be of four different types: a) to maintain most of the features of traditional public administration; b) to modernize the public sector in a selective and gradual process, respecting the existing administrative culture; c) to marketize, which implies a large-scale change, mostly by attributing greater importance to the private sector's organizational techniques; and to d) minimize, which implies making the state machine as small as possible. According to Pollitt and Bouckaert (2011, pp. 115-118), in the cases analysed in their book, there are two subgroups: the marketizers, which include Australia, New Zealand and the UK; and the modernizers, which include Finland, France, the Netherlands, Italy, Sweden, as well as Germany and Belgium, at the subnational level.

\subsubsection{Approach to performance management}

As stated above, within the scope of this paper, performance management is seen as an integrated system where performance information is closely linked to strategic steering. Bouckaert and Halligan (2008, p. 36) consider that a performance management system has three core dimensions: a) measurement, that is, the systematic collection of data on performance; b) incorporation of data related to performance in documents and procedures to eventually use them in the future; and c) use of information for multiple internal or external purposes.

For Bouckaert and Halligan (2008, p. 36), these dimensions have different levels of sophistication and integration across four ideal types of approaches, which are a step forward from the traditional approach towards management: Performance Administration; Management of Performances; Performance Management; and Performance Governance. As the authors mention, these four ideal-types "... can be applied to a certain extent to the historical development of performance and management, as a basis for analysing and comparing country orientations to performance and as a means for thinking analytically about performance management and its components" (Bouckaert and Halligan, 2008, p. 36).

The 'Performance Administration' ideal type is characterized by a systematic administrative registration of data, mostly on inputs and processes, but a limited, disconnected and variable level of incorporation, which is formal and procedural and not necessarily at the core of decision-making. Measurement and incorporation of performance happen mostly as a result of laws and regulations requiring it, which leads to limited use of performance. A classical Weberian bureaucracy fits this model. Countries that fit this type are France and Germany (Bouckaert and Halligan, 2008, pp. $36,50)$.

Within the 'Management of Performances' ideal type, management and performance are linked, although the connection between them is underdeveloped and concurrent 
systems operate. Asymmetrical development of these function-based measurement systems causes them to be not very consistent, coherent, comprehensive or integrated. However, within some functions, there may be a high level of sophistication and development, even up to the level of driving to an improvement and reform processes. The Netherlands and Sweden are examples of countries that fit this type (Bouckaert and Halligan, 2008, pp. 38, 50).

The 'Performance Management' approach is characterized by coherent, consistent and comprehensive measurement systems, which are not just technically sound and functional, but also legitimate. It includes integration of performance information, which goes beyond ad hoc connectedness, for the purpose of using it in a coherent management improvement strategy. Australia, Canada, the UK and the USA fit this type (Bouckaert and Halligan, 2008, p. 38, 50).

The 'Performance Governance' ideal type is grounded on four elements that only a few countries can aspire to have: organizational collaborative relationships exist both within and beyond the public sector, through networks, partnerships and coordination mechanisms; participation and citizen engagement through, for example, community feedback; integration of performance across several organizational levels; and demonstration of performance management's impact on society. No country fits this type (Bouckaert and Halligan, 2008, p. 39).

\section{Methods}

As mentioned above, the aim of this paper is to analyse the state of performance management in the Portuguese public sector as part of the efforts towards public administration reform. In broader terms, and looking at Pollitt and Bouckaert's (2011, p. 13) stages in terms of public sector reforms, we aim to understand if performance management in Portugal is solely at the stage of 'talks' and 'decisions' or if it has reached the stage of 'practices' and 'results'.

To do so, Bouckaert and Halligan's (2008, pp. 35-39) approach was used to analyse the adoption of performance management practices, namely regarding the measurement, incorporation and use of performance information. This approach was supplemented by an adaptation of Pollitt and Bouckaert's (2011, p. 33) framework to analyse the context and trajectories of administrative reforms, by looking at the following variables: socioeconomic forces, including socio-demographic change, global economic forces and socio-economic policies; the political system; and the administrative system.

Mixed techniques were used to assemble data. These comprised documentary analysis, namely legislation and evaluation reports of reform efforts, the analysis of data from secondary sources and a survey conducted with 296 top public managers from the Portuguese Central Public Administration. 
The survey results used are those from the launch of COCOPS Executive Survey ${ }^{3}$ in Portugal, which was sent by e-mail to a total of 1,038 top public managers, which represented the full universe of managers who occupied the first three tiers of Portuguese Central Public Administration organizations, following a common methodology adopted for this survey in all the other participating countries. This survey was distributed in Portugal in late 2012 and early 2013 and had a return rate of 28.5 per cent, with 296 valid answers being obtained. Within the scope of this paper, only certain questions of the original survey were analysed, namely those related to performance management. We started by looking at a question where top public managers were asked about the extent of use of certain management tools in their organizations, using a Likert-type scale, ranging from 1 (not at all) to 7 (to a large extent). From the original set of tools included in the question, we only analysed those considered as performance management tools (business/strategic planning, management by objectives and results, performance-related pay and performance appraisal). Afterwards, we analysed a question where respondents were asked about the extent of measurement practices in their organizations, namely regarding the measurement of inputs, processes and outputs, also using a Likert-type scale ranging from 1 to 7 . Finally, we looked at a question related to the extent of use of performance information according to different purposes, namely: assess own performance; monitor subordinates' performance; identify problems; learn and improve; satisfy superiors' requirements; communicate organizational contribution to users; engage with stakeholders; and, manage the organization's image.

\section{The state of performance management in Portugal}

In this section, the state of performance management in Portugal will be analysed. To do so, we will start by looking at the context and trajectories of administrative reforms, using an adaptation of Pollitt and Bouckaert's (2011, p. 33) framework. We will look at socio-economic forces, the political system, the administrative system and the different phases of the reforms in Portugal. We will then look at the way performance information is being measured, incorporated and used, by using Bouckaert and Halligan's (2008, pp. 35-39) approach.

3 For further information on this survey and to consult the full dataset, please visit https://search.gesis.org/research_data/ZA6598. 


\subsection{The context for performance management}

\subsubsection{Socio-economic forces}

a) Socio-demographic changes

Portugal is a Southern European country, with a population of around ten million. According to the last Portuguese population census, Portugal has one of the oldest populations in the world (with 15.2 per cent of young people and 17.9 per cent of people over 65 , in 2010).

As expected, the ageing of the population has had huge social and economic impacts on the country. According to OECD's reports on social indicators, Portugal's social expenditure (pensions, working-age income support, health and other social services) represented 12.2 per cent of the GDP in 1990, 18.5 per cent in 2000 and 22.6 per cent in 2018 (OECD, 2019, p. 105). This evolution is mostly related to an increase in the old age allowances, which, according to the OECD's statistics portal, represented 67.21 per cent of the total government expenditure in social protection (excluding health) in 2016, while this percentage was 59.72 in 2009 . Unfortunately, this spending did not diminish inequalities. According to the OECD's statistics portal, Portugal had the $6^{\text {th }}$ highest Gini coefficient of the European Union (EU) countries (0.331) in 2016.

\section{b) Global economic forces and socio-economic policies}

After a period of low economic growth in Portugal during the 1970s, due to international crisis and internal political instability related to the 1974 revolution (Andrade and Duarte, 2011), economic growth returned to Portugal in the mid-1980s, following the country's entrance into the European Economic Community (EEC) in 1986 (Pereira and Lains, 2010). Throughout the 1990s, Portugal sustained remarkable economic growth, consistently surpassing the average economic growth rate of EU member states.

The late 1990s and the early 2000s were characterized by a lagging economy. Between 1997 and 2006, Portuguese exports suffered significant losses of market shares, especially in the country's traditional markets (textiles, clothing and footwear), largely due to the presence of new international competitors, namely China and Eastern Europe (Pereira and Lains, 2010).

Economic growth became anaemic after the economic crisis in 2008, with high levels of unemployment and a significant recommencement of emigration. This poor economic situation culminated in the need to request international financial aid and the signing of an Economic Adjustment Programme in May 2011 with the so-called Troika (International Monetary Fund, European Central Bank and European Commission). This pact included a pack of reforms, which will be described later. 


\subsubsection{Political system}

Portugal became a parliamentary democratic republic after the democratic revolution in 1974 and the promulgation of a new Constitution in 1976. After a period of political instability between 1976 and 1985, the Portuguese political system became more stable, with two parties dominating the political sphere - the centre-left PS (Socialist Party) and the centre-right PSD (Social Democratic Party).

The other more traditional parties are the following: the left-wing PCP (Portuguese Communist Party); the left-wing PEV (Green Party), which usually runs for elections in coalition with the PCP; the right-wing CDS-PP (People's Party), which was a junior member of coalition governments with PSD from 2002 to 2005 and from 2011 to 2015; and the left-wing BE (Left Bloc). For the past five years, other parties entered the Parliament: the centrist party PAN (People, Animals and Nature) since 2015; and, since the 2019 elections, the right-wing liberal 'Iniciativa Liberal', the extreme-right wing 'Chega' and the left-wing 'Livre'.

\subsubsection{Administrative system}

The Portuguese administrative system has been influenced by the 'Napoleonic' system, usually being described as having the following characteristics (Corte-Real, 2008): a) a unitary and centralized state, with local governments being the only subnational political actors, without much power; b) Weberian-like legalistic administrative culture; c) politicized relationship between ministers and top public managers, who were politically appointed up to 2012; d) human resources management traditionally based on a career seniority system.

Having looked at the public management context, the next section analyses the way the public sector reform has been implemented in Portugal (phases and process of implementation).

\subsection{The Portuguese public sector reform}

\subsubsection{Phases of the reform}

As several studies demonstrate, NPM and other reformist doctrines have been alive in the political discourse in Portugal and several measures have been implemented, even if they have not always achieved their proposed goals (Magone, 2011; Mota et al., 2016). According to some of these studies, the process of reform became more evident after 1985 and may be divided into three phases, which are described in the following subsections. 


\section{a) First Phase: the modernization period (1986-2001)}

From 1986 onwards, the flow of resources from the EEC and a stable 'new-right' majority government (PSD), in-office between 1987 and 1995, helped to generate an economic boom and pressured for the adoption of administrative reforms. In 1986, the Portuguese government committed itself to modernize the administrative system through the introduction of innovative public management tools, with a focus on 'clients' and service quality and with a major effort of debureaucratization (Corte-Real, 2008).

Additionally, the government tried to end the existing incremental budget approach and to integrate the budget according to the cycle of management: planning, programming, budgeting and control. Public sector organizations were required to produce annual Activity Plans and Activity Reports (Council of Ministers Resolution no. 34/87). Ministers had to approve the Activity Plans of each public service and integrate that information into the overall strategy and into their ministry's budget (Araújo and Branco, 2009). As part of this process, there had to be an articulation between management by objectives and the techniques of budgeting management. Analyses suggest that this reform failed to meet its goal, mostly due to institutional resistance and the almost complete absence of training of senior civil servants in management by results (Araújo and Branco, 2009).

Two socialist governments, in-office between 1995 and 2002, followed a somewhat similar approach to the prior administrative reform. The quality programme was revitalized, with the adoption of the model of the European Foundation for Quality Management (EFQM), while the concern with debureaucratization and citizen-oriented policies was reinforced (Corte-Real, 2008; Magone, 2011). Additionally, agencies (named 'Institutos Públicos'), which had the goal of creating more flexible and autonomous organizations, became more common figures (Corte-Real, 2008).

Furthermore, in 1996, the government tried to revitalize the Activity Plans and Reports. In order to enhance the implementation of these instruments, Decree-Law 183/96 established, for the first time, the participation of all stakeholders in the process, and the availability of the information concerning the activities of public services. However, this instrument had limited influence in changing the management of public services (Araújo and Branco, 2009).

Even though the citizen-oriented initiatives were seen as positive in this phase, the end of this cycle led to serious concern about the level of public expenditure (Corte-Real, 2008). In fact, EU pressure towards budgetary balance compelled the government to rethink both the role of the state and the dimension of public administration. These worries dictated the reforms that were carried out in the next phase. 


\section{c) Second Phase: the control period (2002-2011)}

The unfavourable economic context, on the one hand, and the financial restrictions imposed by the adhesion to the European Monetary Union, on the other, forced the government to adopt reforms closer to the NPM ideas of efficiency, effectiveness and economy, in a scenario that was also favoured by right-wing coalition governments (PSD and CDS) in-office between 2002 and 2005 (Magone, 2011).

As for management practices, in 2004, the government in office established the adoption of management by objectives as the main matrix of change. Within this context, Law 10/2004 created the Integrated Evaluation System for Public Administration (SIADAP) (Madureira, 2016). According to Rocha and Araújo (2007, p. 591), the implementation of SIADAP during this initial period was not successful, as it "was applied to less than 25 per cent of the civil servants, it did not include the evaluation of public organizations in an integrated way, it ignored the quality component, and it was not in agreement with the training program".

The path described was followed by the Socialist governments in-office between 2005 and 2011, which took the first steps towards the renovation of the public administration modernization strategy. In 2005, the government in office implemented the State Central Administration Restructuring Programme (PRACE) (Council of Ministers Resolution $124 / 2005$ ), which sought to reduce the number of public services, aiming to reduce expenses, de-centralize functions, de-concentrate, modernize and automate procedures, and increase efficiency through better management and co-ordination processes (Magone, 2011). Moreover, efficiency and productivity objectives were pursued through the implementation of the Programme for Administrative and Legislative Simplification (SIMPLEX), which was designed to reduce bureaucracy, increase state transparency and foster efficiency in public administration (Huerta Melchor, 2008).

Finally, at the end of 2007, the government decided to revitalize SIADAP (Law 66$\mathrm{B} / 2007$ ). The new SIADAP included the performance assessment of services (SIADAP 1), top and middle-level managers (SIADAP 2) and employees (SIADAP 3). These measures envisioned to create an environment of competition, as the performance appraisal results were intended to have an impact on staff remunerations, career advancement and contract renewals (Huerta Melchor, 2008).

The reforms implemented in this second phase have undoubtedly produced changes in the traditional culture of the Portuguese public service. Nevertheless, public servants were not enthusiastic about the initiatives, believing they affected their working conditions and labour rights (Madureira, 2016). Moreover, those reform efforts were perceived as giving more power to managers (too much from the point of view of the employees), particularly regarding employees' career advancement (Huerta Melchor, 2008). 


\section{d) Third phase: the austerity period (2011-present)}

The international financial and economic crisis that started in 2008 paved the way for a period of austerity and consequent deep reforms in the Portuguese public sector - firstly with three programmes of stability and growth (PECs) approved by the government in office in 2010 and 2011, and, later on, under the 2011-2014 Economic Adjustment Programme (EAP).

The several versions of the EAP - also named Memoranda of Understanding (MoU) - which were implemented by a coalition government formed by PSD and CDS after a change in government in 2011 - included several measures related to the public sector: the privatization of some state-owned companies; the reduction/elimination of the role of the state as a shareholder in other companies; the adoption of a plan to restructure the central administration (PREMAC); the reduction of the number of public servants through hiring freezes and 'friendly termination' options; the reduction of public service salaries and pensions; the restructuring of service provision in the justice, finance and health sectors; and the retrenchment of several welfare benefits (Memoranda Monitoring Structure, 2014). Besides these measures aimed at cost-cutting, other measures were implemented, including the adoption of several e-government and shared services initiatives, the creation of a commission responsible for recruiting top public managers based on merit (CReSAP), and the transference of competences to municipalities and inter-municipal communities (Memoranda Monitoring Structure, 2014).

According to a study carried out by Mota et al. (2016), public managers consider that these reforms led to a worsening of social cohesion and policy coherence and coordination. Moreover, the decision-making processes became more centralized and more dependent on the Ministry of Finance (Mota et al., 2016).

Since 2015, with the end of the bailout period and, later on, with the election of a new government in late 2015, there have been some changes. Those changes are mostly related to the reduction or elimination of freezes or cuts in salaries and pensions, the promotion of the first participatory budget at a national level, and the adoption of the second generation of the bureaucratic simplification programme (SIMPLEX+). Despite some changes, a cost-cutting strategy is still somewhat visible, leading us to consider that a new phase is still not being implemented.

\subsubsection{The implementation of reforms}

There is a strong legalistic culture in the Portuguese public administration, with the legal aspect quite often prevailing over management. Most of the decisions related to the abovementioned reforms were taken at the level of the Council of Ministers and Parliament. As demonstrated by Mota et al. (2016), Portuguese top public managers consider the processes of reform to have been mostly driven by politicians, with a top- 
down approach and without the participation from citizens or support of unions (Mota et $a l ., 2016)$. Likewise, they consider that reforms were rather partial and inconsistent and mostly focused on cost-cutting rather than on service improvement, and hence rather unsuccessful (Mota et al., 2016).

Despite this more pessimistic vision about the trajectory of reform expressed by public managers, the list of reforms described in the previous subsections may not be ignored. Thus, according to Pollitt and Bouckaert's (2011, p. 115-118) typology of trajectories of reform, we may consider that the Portuguese public sector fits the 'Modernizer' type.

\subsection{Measurement, incorporation and use of performance information}

In this section, we will look at the way performance information is being measured, incorporated and used in Portugal, by using Bouckaert and Halligan's (2008, pp. 35-39) approach.

\subsubsection{Measurement}

As described in the previous section, the Portuguese public administration has been undergoing a continuous process of reform since the mid-1970s, although the adoption of more NPM-like reforms became more evident from the late 1990s and early 2000s. In the late 1990s, we witnessed the reinforcement of the development of Activity Plans and Reports. During the first decade of the $21^{\text {st }}$ century, some managerial measures were (re)introduced, including management by objectives and a new performance appraisal system for services and staff (SIADAP).

Looking at these reforms, it is clear that there have been attempts to introduce 'management by results' into the Portuguese public administration. In fact, data from the survey showed that top public managers consider there is significant use of performance tools in their organizations, such as management by objectives and results $(\bar{x}=5.66)$, strategic and business plans $(\bar{x}=5.26)$ and performance appraisal interviews $(\bar{x}=5.22)$. Conversely, there is a very little use of performance-related pay tools $(\bar{x}=1.90)$.

In terms of the extent of measurement practices in their organizations, namely regarding the measurement of inputs, processes and outputs, public managers consider that more importance is given to the measurement of outputs $(\bar{x}=4.78)$ than to the measurement of inputs and processes $(\bar{x}=3.91)$.

The reported results are in line with those revealed in a study on the use of performance management systems in 155 Portuguese agencies and departments (Gomes et al., 2017). According to this study, Portuguese public sector organizations are more likely to collect 
performance information regarding outputs, and less regarding the quality of services or societal effects (Gomes et al., 2017).

\subsubsection{Incorporation}

Concerning the incorporation of the measurements into documents, procedures and policy information, only sporadic reports on the impact of reforms were produced and these were not interconnected. One of the few documents (perhaps the only one) that looked at the impact of the reforms on the Portuguese public sector in an integrated way was the OECD's 1996 report 'Putting Citizens First: Portuguese Experience in Public Management Reform'. Other than that, only periodic reports were produced.

In relation to the implementation of Activity Plans and Reports, no real evaluation was made in this regard. The only official document that mentions the inefficient application of those instruments is Decree-Law 183/96, but it does not explain the reasons for that. One potential reason mentioned by Araújo and Branco (2009) was the lack of training on the topic of management by outputs provided to senior civil servants at that time. After that, no other official assessment was made on the implementation of those instruments.

The only study that was developed on the implementation of Activity Plans and Reports was done by Araújo and Branco (2009), which, based on a survey launched to public organizations in 2002, concluded that the vast majority of the surveyed organizations produced Activity Plans and Reports annually (Araújo and Branco, 2009). Furthermore, the authors also concluded that there was no integration between the Activity Plan and the budget in most cases, as desired by the legislators (Araújo and Branco, 2009).

This lack of integration is reinforced by the results of the 2016 OECD Performance Budgeting Survey. According to this survey, Portugal is one of the few OECD countries with no standard performance budgeting framework and has one of the poorest performances in the 2016 OECD Performance Budgeting Index (0.08 on a $0-1$ scale).

Concerning SIADAP, by Law, all services have to publish the overall result of the service, and the qualitative grades of staff by category on an annual basis. Nevertheless, that information is not available for every service.

\subsubsection{Use of Information}

As mentioned before, the collected performance information can be used for multiple purposes. Concerning the use of Activity Plans and Reports, the study carried out by Araújo and Branco (2009) revealed that survey respondents considered that those documents were produced mostly for legalistic reasons. Most respondents admitted that they adhered to the Activity Plan because it was compulsory, transforming this instrument 
into a mere formality that had to be followed. Moreover, according to their survey respondents, the production of these documents tended to involve only top and middle managers, leaving other civil servants and service users out of the process (Araújo and Branco, 2009).

The results of the survey conducted with 296 top public managers support these arguments. As presented in Figure 1, the respondents stated that they and their organizations used performance information more to monitor their own performance $(\bar{x}$ $=5.70)$ and their subordinates' performance $(\bar{x}=5.66)$ or to satisfy the requirements of their superiors $(\bar{x}=5.24)$, than to identify problems that required attention $(\bar{x}=5.17)$ or to foster learning and improvement $(\bar{x}=4.93)$. Survey respondents also considered that performance information was only fairly used for external purposes, such as to engage with external stakeholders $(\bar{x}=4.41)$, manage the organizations' image $(\bar{x}=4.40)$ or communicate with users of public services $(\bar{x}=4.39)$.

Figure 1. The extent of use of performance information for different purposes in Portuguese public sector organizations (mean values)

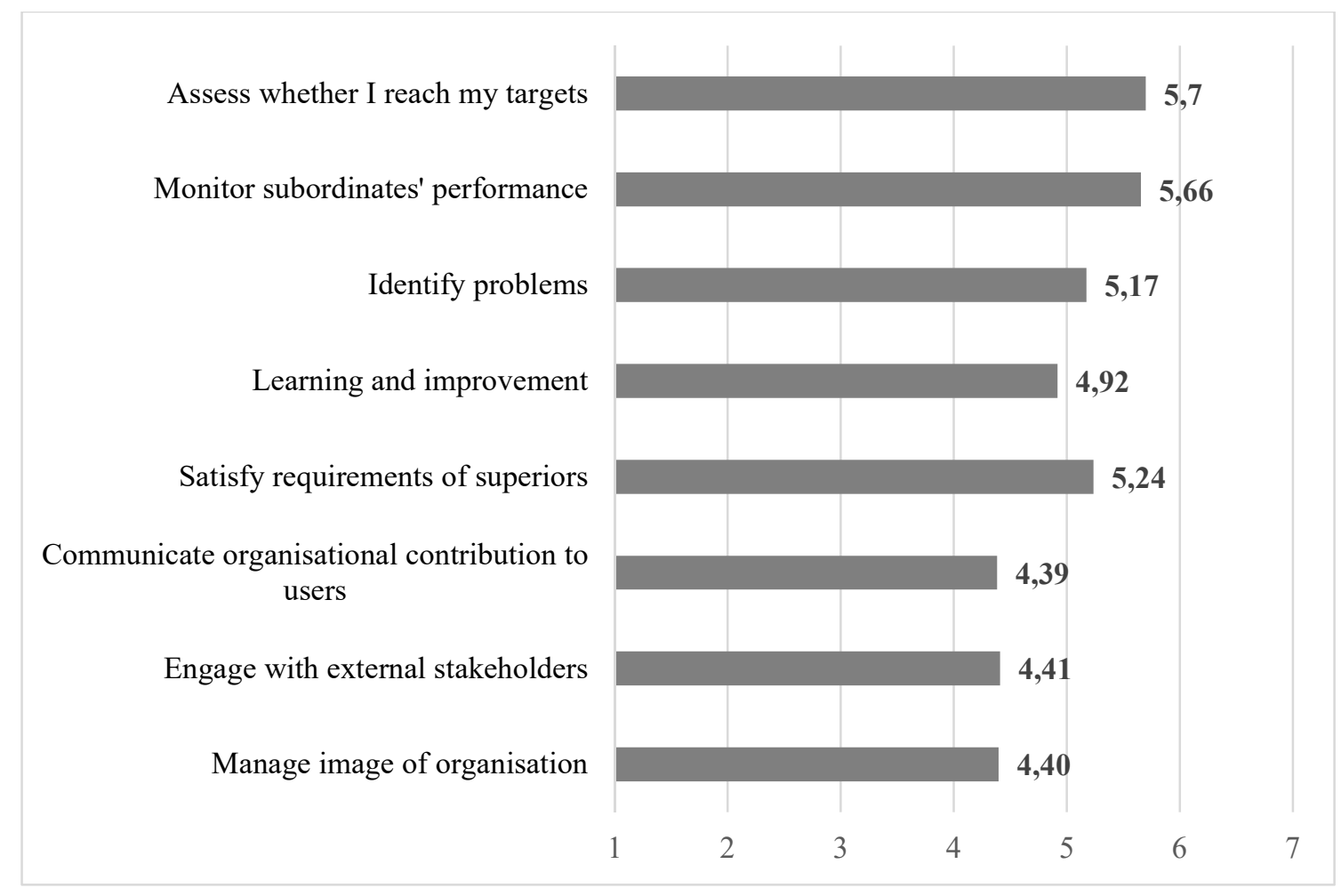

Note: the question was "In my work, I use performance indicators to... " with a Likert-type scale ranging from ' $1=$ Not at all' to ' $7=$ To a large extent'

$\mathrm{N}=296$

Source: based on the results of the COCOPS executive survey (Hammerschmid, 2015) 


\section{Conclusions}

The aim of this paper was to analyse the state of performance management in the Portuguese public sector as part of the efforts towards public administration reform. To do so, we have used Bouckaert and Halligan's (2008, pp. 35-39) approach to analyse the adoption of performance management practices, namely regarding the measurement, incorporation and use of performance information. Additionally, an adaptation of Pollitt and Bouckaert's (2011, p. 33) framework was used to analyse the context and trajectories of administrative reforms.

The research conducted showed that the Portuguese public sector adopted several NPM-like reforms, which implied the use of an increasing number of managerial tools, including performance management tools, such as management based on objectives and results, strategic and business plans and performance appraisal. The creation of instruments such as Activity Plans and Reports (created in 1987 and further expanded in 1996) and the Integrated Evaluation System for Public Administration (SIADAP, created in 2004 and expanded in 2007) are perhaps the best examples of such efforts.

However, even though these tools are used to a significant extent in the Portuguese public sector, there is a limited level of incorporation of performance information. In fact, the measurement of performance and the reporting of that data seems to happen not because organizations want to do it for policymaking or management purposes, but because laws and regulations are requiring it. As the documentary analysis conducted showed, the incorporation of the measurements into documents, procedures and policy information is sporadic, with reports on the impact of reforms being scarcely produced and not interconnected.

The research also indicates that performance information is mostly used for monitoring top managers' performance and their subordinates' performance and for internal accountability purposes (namely to satisfy the requirements of their superiors), rather than for learning and improvement, to identify problems or for external purposes, such as communicating with stakeholders and users of public services. These problems are therefore in line with the most common problems related to performance management identified by Van Dooren and Hoffmann (2018).

Looking at Pollitt and Bouckaert's (2011, p. 13) stages in terms of public sector reforms, it can be stated that there seem to be more 'talk' and 'decisions' than 'practice' and 'results' on what concerns the adoption of performance management in Portugal. As we have seen throughout this paper, the concept of performance management was indeed introduced in the 'lexicon' of the Portuguese public sector and several decisions about performance management were made by the government. However, performance management is only timidly incorporated into practices and used for internal and external purposes, which may lead us to assume it does not often lead to an improvement of results. 
The Portuguese experience also shows that to effectively incorporate change into the culture of the public sector, it is advisable to do it gradually, along with a good strategy of communication and training, where all stakeholders understand what has changed and why. As reported before, the early stages of implementation of instruments, such as Activity Plans and SIADAP, were not successful due to lack of integration with other practices and to institutional resistance, partially because top public managers were not trained and they were not involved in the change process (Rocha and Araújo, 2007; Araújo and Branco, 2009). These conclusions are therefore in line with the aforementioned drivers of data use suggested by Kroll (2015), who highlights the importance of involving stakeholders or the existence of an innovative culture or goal clarity.

Given the above, in terms of the ideal types of public sector performance management proposed by Bouckaert and Halligan (2008, pp. 36-39), we consider that Portugal would better fit the 'Performance Administration' ideal type, even though there are some signs that it is moving closer to the 'Managements of Performance' ideal type.

These findings will be of interest to scholars who study public administration reforms and performance management and to Portuguese policymakers and public managers who are interested in understanding the state of performance management in the Portuguese public sector and in improving the way performance is measured, incorporated and used in that sector.

\section{References}

Andrade, J., and Duarte, A. (2011), "The Fundamentals of the Portuguese Crisis", Panoeconomicus, Vol. 58 No. 2, pp. 195-218.

Araújo, J. and Branco, J. (2009). "Implementing Performance-based Management in the Traditional Bureaucracy of Portugal”, Public Administration, Vol. 87 No. 3, pp. 557573.

Askim, J. (2008), "Determinants of Performance Information Utilization in Political Decision Making", Van Dooren, W. and Van De Walle, S. (Eds.), Performance Information in the Public Sector: How it is Used, Palgrave Macmillan, Houndmills, pp. 125-139.

Boland, T. and Fowler, A. (2000), "A Systems Perspective of Performance Management in Public Sector Organisations", The International Journal of Public Sector Management, Vol. 13 No. 5, pp. 417-446.

Bouckaert, G. and Halligan, J. (2008). Managing Performance: International Comparisons, Routledge, New York. 
Bouckaert, G. and Van Dooren, W. (2003), "Performance Management on Public Sector Organizations", Löffler, E. and Bovaird, T. (Eds.), Public Management and Governance, Routledge, London, pp. 127-136.

Corte-Real, I. (2008), "Public management reform in Portugal: successes and failures", International Journal of Public Sector Management, Vol. 21 No. 2, pp. 206-229.

Gomes, P., Mendes, S. and Carvalho, J. (2017), "Impact of PMS on organizational performance and moderating effects of context", International Journal of Productivity and Performance Management, Vol. 66 No. 4, pp. 517-538.

Haas, M. D. and Kleingeld, A. (1998), "Multilevel Design of Performance Measurement Systems: Enhancing Strategic Dialogue through the Organization", Management Accounting Research, Vol. 10 No. 3, pp. 223-261.

Hammerschmid, G. (2015), COCOPS Executive Survey on Public Sector Reform in Europe - Views and Experiences from Senior Executives - Full Version [Dataset]. GESIS Data Archive, Cologne. ZA6598 Data file Version 1.0.4, available at http://doi.org/10.4232/, 2015 (accessed 12 January 2020)

Hammerschmid, G., Van de Walle, S. and Stimac, V. (2013), "Internal and external use of performance information in public organizations: results from an international survey", Public Money and Management, Vol. 33 No. 4, pp. 261-268.

Hansen, M. B. (2017), "Performance Management and Evaluation", Greve, B. (Ed.), Handbook of Social Policy Evaluation, Edward Elgar Publishing, London, pp. 223241.

Hatry, H. P. (2006), Performance Measurement: Getting Results, Urban Institute Press, Washington, DC.

Huerta Melchor, O. (2008), "Managing Change in OECD Governments: An Introductory Framework", OECD Working Papers on Public Governance, 12, OECD, Paris.

Kroll, A. (2015), "Drivers of performance information use: Systematic Literature Review and Directions for Future Research", Public Performance \& Management Review, Vol. 38 No. 3, pp. 459-486.

Lægreid, P. and Verhoest, K. (2010), Governance of Public Sector Organizations: Proliferation, Autonomy and Performance, Palgrave Macmillan, Basingstoke.

Lægreid, P., Roness, P. G. and Rubecksen, K. (2008), "Performance Information and Performance Steering: Integrated System or Loose Coupling", Van Dooren, W. and Van De Walle, S. (Eds.), Performance Information in the Public Sector: How it is Used, Palgrave Macmillan, Houndmills, pp. 42-57.

Madureira, C. (2016), "Sistema Integrado de Avaliação de Desempenho na Administração Pública Portuguesa (SIADAP) - Balanço de uma década [Public 
Administration Integrated Performance Assessment System (SIADAP) - the balance of a decade]", Lusíada Economia e Empresa, Vol. 20, pp. 171-194.

Magone, J. (2011), "The difficult Transformation of State and Public Administration in Portugal: Europeanization and the persistence of neo-patrimonialism", Public Administration, Vol. 89 No. 3, pp. 756-782.

Memoranda Monitoring Structure (2014), The Management of the Adjustment Programme: 1000 days, 450 enforced measures, Portuguese Government, Lisbon.

Mota, L. F., Cardim, M. E. and Pereira, L. (2016), "Public Sector Reform in Portugal: a path between service improvement and cutback measures", Hammerschmid, G., Van de Walle, S., Andrews, R. and Bezes, P. (Eds.), Public Administration Reforms in Europe: The View from the Top, Edward Elgar, Cheltenham, pp. 194-204.

Moynihan, D. (2008), "Advocacy and Learning: An Interactive-Dialogue Approach to Performance Information Use", Van Dooren, W. and Van De Walle, S. (Eds.), Performance Information in the Public Sector: How it is Used, Palgrave Macmillan, Houndmills, pp. 24-41.

Moynihan, D. P. and Hawes, D. P. (2012), "Responsiveness to reform values: the influence of the environment on performance information use", Public Administration Review, Vol. 72 No. 1, pp. 95-105.

OECD (2019) Society at a Glance 2019: OECD Social Indicators. OECD Publishing, Paris.

Pereira, Á. S. and Lains, P. (2010), "From an Agrarian Society to a Knowledge Economy: Portugal, 1950-2010", Working Papers in Economic History WP10-09, Universidad Carlos III, Madrid.

Pollitt, C. and Bouckaert, G. (2011), Public Management Reform: A Comparative Analysis - New Public Management, Governance, and the Neo-Weberian State (3rd. edition), Oxford University Press, New York.

Pollitt, C. (2013), "The Logics of Evaluation", Evaluation, Vol. 19 No. 4, pp. 346-363.

Radnor, Z. and Barnes, D. (2007), "Historical Analysis of Performance Measurement and Management in Operations Management", International Journal of Productivity and Performance Management, Vol. 56 No. 5/6, pp. 384-396.

Rhodes, M. L., Biondi, L., Gomes, R., Melo, A. I., Ohemeng, F., Perez-Lopez, G., Rossi, A. and Sutiyono, W. (2012), "Current State of Public Sector Performance Management in Seven Selected Countries", International Journal of Productivity and Performance Management, Vol. 61 No. 3, pp. 235-271. 
Rocha, J. A. O. and Araújo, J. (2007), "Administrative reform in Portugal: problems and prospects", International Review of Administrative Sciences, Vol. 73 No. 4, pp. 583596.

Van De Walle, S. and Van Dooren, W. (2008), "Introduction: Using Public Sector Performance Information", Van Dooren, W. and Van De Walle, S. (Eds.), Performance Information in the Public Sector: How it is Used, Palgrave Macmillan, Houndmills, pp. 1-8.

Van Dooren, W. (2006), Performance Measurement in the Flemish Public Sector: A Supply and Demand Approach. PhD Thesis, K.U. Leuven, Leuven.

Van Dooren, W., and Hoffmann, C. (2018), "Performance Management in Europe: An Idea Whose Time Has Come and Gone?", Ongaro, E. and Van Thiel, S. (Eds.), The Palgrave Handbook of Public Administration and Management in Europe, Palgrave McMillan, Basingstoke, pp. 207-225.

Van Dooren, W. and Van de Walle, S. (2008), Performance Information in the Public Sector: How it is Used. Palgrave Macmillan, Houndmills.

Van Dooren, W., Bouckaert, G., and Halligan, J. (2010), Performance Management in the Public Sector. Routledge, New York. 